\title{
Corruption, Investment and Economic Growth in Developing Countries: A Panel Smooth Transition Regression Approach
}

\author{
Yann Harold Nounamo Nguedie
}

$\mathrm{PhD}$ Student in Economics, Faculty of Economics and Management, University of Yaoundé II-SOA, Cameroon

\begin{abstract}
This article analyzes for a sample of 110 countries between 2006-2016, the relationship between corruption, investment and growth. Using the Panel Smooth Transition Regression (PSTR), results show that there is a non-linearity between growth and investment which depends on the level of corruption, characterized by a smooth transition between the two extreme regimes. More precisely, the results obtained suggest that the sensitivity of growth to investment is higher in countries with a low degree of corruption. By elsewhere we also find a positive direct impact of the corruption on growth.
\end{abstract}

Keywords: growth, investment, corruption, panel smooth threshold regression.

JEL Classification: E22, G11, O16, O55.

(C) The Author, 2018. This article is published with open access at Sumy State University.

\section{Introduction}

Investment is a key element in the fight against poverty. Thus, as pointed out by Barro and Sala-i Martin (2004), the differences in growth rates may explain the income disparities that exist between countries. Identify the factors that contribute to investment and those that hinder it are the foundation of basis to fight against poverty. This is why investment is part of many developments in economic literature. For example, since the emergence of the theory of growth, many factors have been identified as determinants of growth. The most important contribution of the theory of neo-classical growth is Solow (1965) who considers technical progress as the engine of growth. More recently, with the new theories of endogenous growth, other economists like Romer (1990) consider that human capital is the source of growth. Whereas Barro (1990) believes public spending would play an important role. The above factors have served as a basis for the World Bank's policies.

After a few decades, it is clear that these policies have failed, which has led to questions about causes of this failure. Among the proposed answers, North (1990) argues the importance of the role played by institutional factors. For instance, Mauro (1995) suggests that corruption is one of main obstacles to growth. Since then, work on corruption has multiplied. Most of them lead to the conclusion that corruption would be detrimental to growth. However, there are, some more recent theoretical work leading to more nuanced results. It has been shown that corruption has an impact on growth essentially through indirect effects. One of the main channels of transmission through which corruption affects growth is investment. That's why this paper focuses on studying the relationship between growth and investment conditionally to corruption. On the other hand, because of the existence of multiple equilibrium in many theoretical models relating to the subject and the fact of the existence of mixed results, this relationship could be non-linear. In order to highlight this nonlinearity, we will resort to recent econometric methods, Panel Smooth Transition Regression (PSTR) proposed by Gonzales et al. (2005). We show, on the one hand, that there is a non-linear relationship between growth and investment in through corruption. Countries with high levels of corruption would have lower growth sensitivity to investment than low level of corruption. On the other hand, our results suggest that the direct effect of corruption on growth is positive.

The rest of the paper is organized as follows. Section 2 presents the literature review. Section 3 demonstrates the methodology and data sources. Section 4 reports the empirical results. Finally, section 5 provides the conclusion.

\section{Literature review}

For many economists, corruption is the main reason justifying the insufficiency or overestimation of investments (Knack, 2003). Burguet and Che (2004) show that corruption has a detrimental effect on free competition and the quality of parities provided for example by a selected firm following a call for tenders. The 
question of the interrelations that may exist between foreign direct investment and corruption was addressed by Habib and Zurawicki (2002) and by Larrain and Tavares (2004). These authors show that corruption has a negative impact on cooperation, whatever the meaning of the whether it is the donor country or the recipient country. They emphasized all that corruption is at the root of the inefficiency of investments. In a study highlighting the perverse effects of corruption, Fedeli and Forte (2003) explain that in the absence of corruption, the performance of a centralized system and a decentralized system are identical in terms of nancing of private projects. The work of Sakar and Aynul (2001) is in the same logic. They believe that corruption is the source of the additional transaction costs. As such, it reduces both the volume of investments and their efficiency and beyond undermines economic growth. They are convinced that less corruption is corollary additional earnings.

Studies on the interrelation between investments and corruption and growth in Africa were also conducted. In a historical approach, Collier (2000) mentions that Africa has not always been a broken continent as well as African societies. Unfortunately, this is a problem that is gaining ground and most African countries are doing today their priority with regard to these perverse effects.

Unlike this author, Hope and Chikulo (2000) draw up an analytical table of theory, practice and the impact on the development of corruption in Africa. They show how in some countries, corruption has contributed to the degradation of infrastructures, rendered inefficiently the rehabilitation investments of very health, educational facilities, etc. The contribution of Gyimah-Brempong (2002) confirms the conclusions of Hope and Chikulo.

It may be noted, in view of the foregoing, that the volume and the character of productive public and private investments are affected by the scale of corruption in a country and the absence of the obligation to render account to the hierarchical authority. The combined effects of these factors tarnish economic performance indicators.

\section{Methodology and data}

There are two main types of threshold modeling: the modeling proposed by Hansen (1999) and that of Gonzalez et al. (2005). In Hansen's (1999), non-linearity is reflected in the dependent variable and generated by two separate processes. We are in one process or another depending on the value taken by a variable called transition variable. In our case, the transition variable will be the corruption. Under this specification, the model to estimate would be the following:

$g_{i t}=\mu_{i}+a_{1} I_{i t}+a_{2} I_{i t} \Gamma\left(q_{i t}, c\right)+a_{3} C_{i t}+a_{4} X_{i t}+\varepsilon i t$,

with: $\mu_{i}$ is the individual fixed effect, $I$ is the investment rate, $C_{i t}$ is the corruption, $X$ is a set of control variables, $q_{i t}$ is the transition variable, who will be here, corruption. The function $\left(q_{i t}, c\right)$ is the transition function and is an indicator function:

$$
\Gamma\left(q_{i t}, c\right)=\left\{\begin{array}{lll}
1 & \text { si } q_{i t}>0 \\
0 & \text { si } q_{i t}<0
\end{array}\right.
$$

The direct effect of corruption on growth is measured across the coefficient $a_{3}$. The indirect effect, he passes through the investment and is measured through $a_{2}$. Under this specification, the linearity test consists of checking whether the parameter $a_{2}$ is different from 0 . The associated hypotheses are written as follows:

$$
H_{0}: a_{2}=0 \text { vs } H_{1}: a_{2} \neq 0
$$

Under the assumption of linearity, the sensitivity of the growth rate investment ratio would be equal to $a_{1}$. Otherwise, she would be equal to $a_{1}+a_{2}$. Hansen's (1999) modeling assumes that the transition between two regimes is brutal. In fact, we are in the dynamics of a process or in the other. However, instead to be brutal, this transition is rather smooth. PSTR modeling proposed by Gonzales et al. (2005) can model situations where the transition from one regime to another is done gradually. So, the transition function will be, not an indicator, but rather a continuous function. PSTRs can also be seen as models in which there are two extreme regimes between which there would have a continuum of regimes.

Under PSTR modeling, the model to estimate is presented as follows: 


$$
g_{i t}=\mu_{i}+a_{1} I_{i t}+a_{2} I_{i t} f\left(q_{i t} ; \gamma, c\right)+a_{3} C_{i t}+a_{4} X_{i t}+\varepsilon_{i t},
$$

Where the transition function is $f\left(q_{i t} ; c\right)$ is continuous and depends on $q_{i t}$ the transition variable, the slope of the transition function and c the centering parameter. Gonzalez et al. (2005) just like Granger and Teräsvirta (1993) use a logistic transition function, whose form is as follows:

$$
f\left(q_{i t} ; \gamma, c\right)=\left[1+\exp \left(-\gamma\left(q_{i t}-c\right)\right)\right]^{-1}
$$

with $\gamma>0$ the slope of the transition function $f($.$) .$

Analysis on PSTR Relative to PTR Specification from Hansen (1999) presents several advantages. In our case, it allows the elasticity of growth relative to investment to vary not only in time, but also according to the country according to the degree of corruption. Thus, the PSTR modeling makes it possible to take into account the heterogeneity of the relationship between growth, investment and corruption. Another advantage of PSTR is that it is a generalization of the PTR.

Corruption is generally assessed through indicators of corruption. Among the best-known, we can mention the Corruption Perception Index (CPI) of Transparency International, the indicator Control of Corruption built by Kaufman et al. or the index of corruption of the ICRG. The CPI is the most publicized and therefore, one of the best known. The indicator of the ICRG has the advantage of offering a wide panel both in the individual and temporal dimension. In this paper, we will use the World Bank's Control of Corruption Index in our estimates. In fact, the governance indicators of the WGI database are considered to be the better built. It is a composite indicator based on people's perceptions of corruption. It ranks countries on a scale from -2.5 to $2.5 ;-2.5$ corresponding to a high level of corruption and 2.5 to low corruption. The index here has been cropped so to obtain positive values ranging from 0 to 5 .

The macroeconomic data used for the estimates are from the World Development Indicators database of the Bank World. Our database is in the form of a panel made up of 110 countries over a period of 11 years. The data starts in 2006 to end in 2016. The endogenous variable is the rate of economic growth (GROWTH). The control variables are: INVEST, which is the ratio to the GDP of the investment, the rate of inflation (IN$F L A T)$ measured by the growth rate of the price index to the consumption, the ratio of public expenditure to $G D P(G O V)$, opening rate $(O P E N)$ which is the sum of imports and exports compared to GDP. Table 1 presents some descriptive statistics for these different variables. The results obtained from the descriptive analysis show that the average level growth on the sample studied is $3.15 \%$, while the corruption index amount to 2,48 .

Table 1. Descriptive statistics

\begin{tabular}{|c|c|c|c|c|c|c|}
\hline Variable & Growth & Corruption & Invest & Gov & Open & Inflation \\
\hline Mean & 4.156 & 3.481 & 12.07 & 15.14 & 83.759 & 11.3 \\
\hline St. dev. & 5.64 & 2.019 & 1.67 & 6.507 & 47.896 & 35.014 \\
\hline Min. & 22.229 & -0.6 & 3.08 & 2.87 & 15.864 & -9.891 \\
\hline Max & 68.541 & 5.000 & 72.894 & 70.542 & 373.509 & 1196.67 \\
\hline
\end{tabular}

\section{Results}

The results of the PSTR estimation of the relationship between growth and investment using as transition variable the level of corruption will be presented in three stages: first the tests of non-linearity, then the estimation of the PSTR model and finally, the sensitivity of the growth to the investment according to the corruption.

\subsection{Linearity test}

The results of the non-linearity tests are presented in Table 2 . We present successively the results of three statistical tests previously described. These results make it possible to reject the hypothesis linearity of the relationship between growth and inflation. So we can conclude that corruption may be considered a potential source of non-linearity. 
Table 2. Linearity test

\begin{tabular}{|c|c|c|c|}
\hline & LM & LM & Pseudo-LRT \\
\hline Statistic & 4,301 & 3,124 & 4,810 \\
\hline P-value & 0,038 & 0,061 & 0,048 \\
\hline
\end{tabular}

\subsection{Estimation}

The estimated model is of PSTR type with growth as variable endogenous and corruption as a transitional variable. The transition is about investment. Table 3 shows the relative coefficients to the estimation of the model. Investment is not significant in the regression. An explanation for this result could be the fact that effects of investment are already captured by the non-linear term of the regression equation. The sensitivity of growth to investment will be represented by $0,217^{*} \mathrm{~g}()$. In the end, the sensitivity of growth to investment is higher in countries characterized by strong corruption. Conversely, in countries where corruption is low, growth is less sensitive to investment. On the other hand, the direct effect Corruption on growth, measured by the coefficient of the variable, Corruption, would be positive. This result reflects the effect of "greasing the wheels" of corruption found in many authors in the literature. Concerning the other control variables, we find that the rate of inflation and the government spending ratio have a negative effect on growth while the impact of the opening rate is positive.

Table 3. Estimation

\begin{tabular}{|c|c|c|c|c|}
\hline \multicolumn{5}{|c|}{ Parameter and transition variables } \\
\hline Variable & Invest & Invest $*^{*}()$ & $\gamma$ & $c$ \\
\hline Coefficient & 0.185 & $0.0217^{* * *}$ & $5.211^{* * *}$ & 1.601 \\
\hline St.Dv & 0.160 & 0,052 & 2,300 & 0.082 \\
\hline
\end{tabular}

Table 4. Other variables

\begin{tabular}{|l|c|c|c|c|}
\hline Variable & Corruption & Govern & Open & Inflation \\
\hline Coefficient & $-0.168^{* *}$ & $-4.26 * * *$ & $0,910^{* * *}$ & $-0,494 *$ \\
\hline St.Dev. & 0.055 & 0.132 & 0.125 & 0.210 \\
\hline
\end{tabular}

Notes: $* * *=1 \%, * *=5 \%, *=10 \%$.

We also find that the centering parameter is of the order of 1.6 while the slope of the transition function is 5,211 . This relatively low slope reflects a smooth transition from investment to growth versus corruption. Figure 1 represents the sensitivity of growth to investment according to the level of corruption. For high levels of corruption (that is, index below about 1.6), the sensitivity of growth to investment is relatively weak. Whereas for low levels of corruption, this sensitivity is higher. On this chart, it is also possible to identify two extreme regimes. The first being characterized by a high level of corruption and low sensitivity of growth to investment. The second presents little corruption and sensitivity from growth to higher investment. Between these two regimes, the transition is smooth.

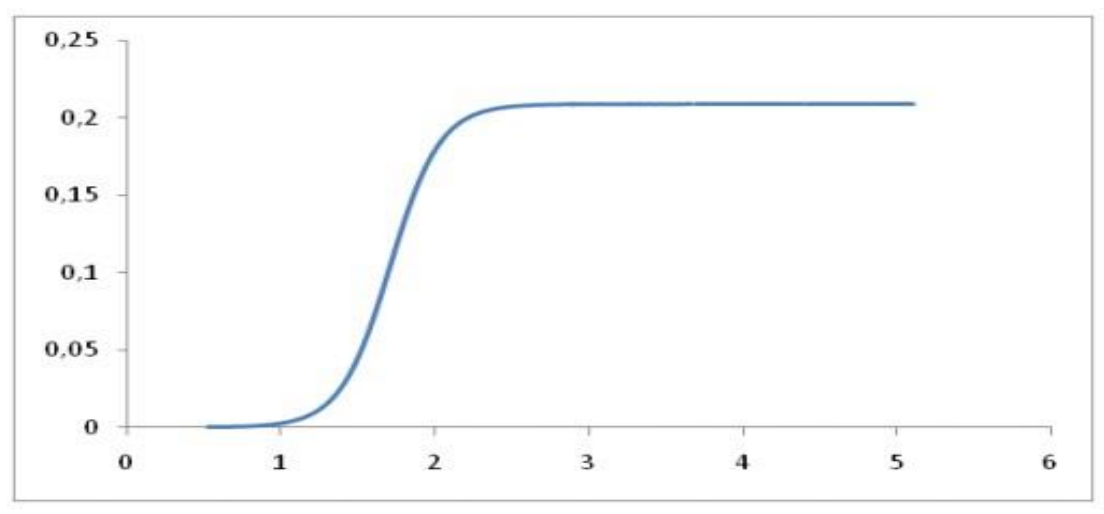

Figure 1. Elasticity of growth to investment according to corruption 


\section{Conclusion}

This article highlights the non-linearity between investment and growth through corruption from a panel of 110 countries over a period of study from 2006 to 2016. Using the recent Panel Smooth Transition Regression (PSTR) methodology, we show that it there is a non-linear relationship between growth and investment. This non-linearity results in a lower sensitivity of growth to investment in countries with high corruption. On the other hand, in countries where the level of corruption is low, growth is more sensitive to changes in the investment. Also, we find that this relationship is characterized by two extreme regimes, one with strong corruption and low sensitivity, and the other with low corruption and high sensitivity. Between these two extreme regimes, there is a smooth transition that can also be interpreted as a "continuum" of schemes. In summary, our results suggest that the harmful effects of corruption on growth through investment are greater in high-corruption countries than in low-corruption countries.

\section{References}

1. Acemoglu, Daron, Johnson, Simon and Robinson, James A. (2004). Institutions as the Fundamental Cause of Long-Run Growth. CEPR Discussion Papers, No. 4458.

2. Barro, Robert J. nd Sala-i-Martin, Xavier (2004). Economic Growth, Second edition.

3. Barro, Robert J. (1990). Government Spending in a Simple Model of Endogenous Growth. Journal of Political Economy, University of Chicago Press, 98(5), 103-126.

4. Ben Salem Melika and Perraudin Corinne (2001). Tests de linéarité, spécification et estimation de modèles à seuil: une analyse comparée des méthodes de Tsay et de Hansen. Économie et Prévision, 148, 157-176.

5. Burguet R. and Y.-K. Che (2004). Competitive Procurement with Corruption. Rand Journal of Economics, 33(1), 50-68.

6. Caner, Mehmet, and Hansen Bruce, E. (2004). Instrumental Variable Estimation of a Threshold Model. Econometric Theory, 20(5), 813-843. 7.

7. Colletaz, Gilbert and Hurlin, Christophe (2006). Treshold Effects of the Public Capital Productivity: an International Panel Smooth Transition Approach. LEO, Université d'Orléans, Working Paper.

8. Collier, P. (2000). How to Reduce Corruption. African Development Review, 12(2), 191-205.

9. Davies, Robert (1987). Hypothesis Testing When a Nuisance Parameter is Present Only Under the Alternative. Biometrika, 74, 33-34.

10. Fedeli, S. and Forte, F. (2003). Public Co-financing of Private Sector's Investments: Subsidiarity and Corruption. Public Choice, 116(1-2), 109-145.

11. Fouquau, Julien, Hurlin, Christophe and Rabaud, Isabelle (2008). The Feldstein-Horioka Puzzle: a Panel Smooth Transition Regression Approach. Economic Modelling, 25(2), 284-299.

12. González Andrés, Teräsvirta Timo et van Dijk Dick (2005). Panel smooth Transition regression Models. Working Paper Series in Economics and Finance, No. 604, Stockholm School of Economics.

13. Granger, Clive W.J. and Teräsvirta, Timo (1993). Modelling nonlinear economic relationships. Oxford University Press.

14. Gyimah-Brempong, K. (2002). Corruption, Economic Growth and Income Inequality in Africa. Economics of Governance, 3(3), 183-209.

15. Habib, M. et Zurawicki, L. (2002). Corruption and Foreign Direct Investment. Journal of International Business Studies, 33(2), 291-307.

16. Hansen, Bruce E. (1999). The treshold effects in non-dynamic panel : estimation, testing and inference. Journal of Econometrics, 93, 345-368

17. Hope, K.R. and Chikulo, B.C. (2000). Corruption and Development in Africa: Lessons from Country Case Studies. Palgrave.

18. Knack, S. (2003). Democracy, governance and growth. Ann Arbor: University of Michigan Press.

19. Larrain, B.F. and Tavares, J. (2004). Does Foreign Direct Investment Decrease Corruption? Cuadernos de Economia, 41(123), 217-230.

20. Lucas, Robert (1998). On the Mechanics of Economic Development. Journal of Monetary Economics, 22(1), 3-42.

21. Mauro, Paolo (1995). Corruption and growth. Quarterly Journal of Economics, 110(3), 681-712.

22. Mauro, Paolo (2004). The Persistance of Corruption and Slow Economic Growth. IMF Staff Papers, $51(1), 1-18$. 
23. Minea, A. and Villieu, P. (2008). Un réexamen de la relation non linéaire entre déficits budgétaires et croissance économique. Revue Economique, 59, 561-570.

24. Minier, Jenny (2007). Nonlinearities and Robustness in Growth Regressions. American Economic Review, 97(2), 388-392.

25. OCDE (2007). Les indicateurs de gouvernance: usages et abus. Etudes du Centre de Développement, No. 11.

26. Pellegrini, Lorenzo, and Gerlagh, Reyer (2004). Corruption's Effect on Growth and Its Transmission Channels. Kyklos, 57(3), 429-456.

27. Romer, Paul M. (1990). Are Non convexities Important for Understanding Growth? American Economic Review, 80(2), 97-103.

28. Sarkar, H.H. and Aynul, M. (2001). Impact of Corruption on the Efficiency of Investment: Evidence from A Cross-Country Analysis. Asia-Pacific Development Journal, 8(2), 111-116.

29. Solow, Robert M. (1956). A Contribution to the Theory of Economic Growth. Quarterly Journal of Economics, 70, 65-94.

30. Swaleheen, Mush and Stansel, Dean (2007). Economic Freedom, Corruption, and Growth. Cato Journal, 27(3), 343-358. 